\title{
Promoting Resident Emotional Health Meaningful Connections: An Evaluation of a Wellness Game
}

\author{
Bruce St. Amour, $\mathrm{DO}^{1}$ and William B. DeHart, $\mathrm{PhD}^{2}$
}

\begin{abstract}
Introduction: Physician wellness is a topic of significant national interest. Physician burnout is at its highest point during residency and is linked to many negative outcomes. The Core Emotional Needs are a useful framework to guide thinking toward wellness in residents: connection and acceptance, healthy autonomy and performance, reasonable limits, and healthy responsibility and standards. We examined the efficacy of a game ("Well, For Me...") designed to improve social connection and acceptance among residents to reduce social isolation. We hypothesized that this activity would be viewed positively by the residents as an intervention to improve resident wellness.

Methods: Participants from three programs played a newly developed game in which players take turns answering questions requiring degrees of self-disclosure. More "applause" points are scored with increasing self-disclosure. Subjects completed an anonymous self-administered evaluation immediately after playing the game. After the survey, a group interview was conducted.

Results: Games lasted 40-45 minutes and required no preparation. Of a possible 70 participants, 47 (67\%) completed the survey (10 Likert-Style questions from strongly disagree (1) to strongly agree (5)). Scores related to increased connection and acceptance averaged 4.15. Grouped themes support the survey data - those items that scored higher deal with connection to others. The intervention was well received by the participants.
\end{abstract}

Conclusion: Playing "Well, For Me..." demonstrated the capacity to provide the connection and acceptance from peers necessary to limit social isolation and support resident wellness.

DOI: 10.18297/jwellness/vol2/iss2/3

Received Date: May 11, 2020 Accepted Date: August 11, 2020 Publication Date: Sep 01, 2020 Website: $\underline{\text { https://ir.library.louisville.edu/ }}$ jwellness/

Recommended Citation: St. Amour, Bruce DeHart, William B. (2020) " Promoting Resident Emotional Health Meaningful Connections: An Evaluation of a Wellness Game" Journal of Wellness: Vol. 2 : Iss. 2 , Article 3.

Affiliations: ${ }^{1}$ LewisGale Medical Center Department of Emergency Medicine, ${ }^{2} \mathrm{HCA}$ (Hospital Corporation of America) Healthcare; Capital Division, VA

\section{INTRODUCTION}

Physician wellness has recently been a topic of significant national interest [1-8]. The term "wellness" has many definitions, perhaps best defined by Around et al. as "one's personal recipe for thriving and not just surviving" [1]. Wellness refers to interconnected dimensions of physical, mental, and social well-being that extend beyond the absence of illness. Wellness has traditionally been measured in the negative sense by assessing rates of burnout, emotional exhaustion, and depersonalization. At its highest point during residency, physician burnout is linked to many negative outcomes: substance abuse and suicidal idealization by the physician [1, $4,5]$. Most researchers have focused on organizational-level interventions such as corporate wellness or resilience training to reduce burnout, although individual level interventions such as meditation and mindfulness have shown promise in reducing burnout [2].

Several wellness curriculums have been proposed for residents, but there is little evidence of specific activities or interventions that to include in these curricula [8]. The Accreditation Council for Graduate Medical Education set a mandate to address resident wellness in the Common Program requirements; however, specific, validated strategies and interventions are not well-established [9]. There is a need for recommended interventions, validated through assessment, and these interventions should be further developed.

We developed a game entitled "Well, For Me...," which consists of targeted questions that residents take turns answering. Each question requires a degree of self-disclosure,

*Correspondence To: Bruce St. Amour

Email: bruce.stamour@hcahealthcare.com

which is necessary to build deeper connection and acceptance. This self-disclosure can be uncomfortable in a group of strangers, so we used a gamification strategy to motivate residents to make meaningful contributions. Gamification is the application of game elements in non-game contexts, which in this case is peer bonding [10].

Our objective is to examine the efficacy of a game designed to improve social connection and acceptance and whether this activity is useful in building social bonds with fellow residents to reduce social isolation. Our hypothesis is that this activity would be viewed positively by the residents as an intervention to improve resident wellness.

\section{METHODS}

In this mixed-methods design, participants from three programs in a community hospital played "Well...For $\mathrm{Me}$ " in small groups. The game took place within a wellness event near the end of the academic year in June or as part of intern orientation in July. Those who chose to participate completed a self-administered Wellness Activity Evaluation Form immediately after completion of game play. Participants and non-participants were not followed longitudinally, to alleviate any possible risks (e.g., stigmatized as a "non-team player") of non-participation. Creating a "safe" environment for disclosure was essential to limit stress and anxiety, though mild discomfort could be unavoidable for some participants. After participants

Copyright: @ 2020 The author(s). This is an open access article distributed under the terms of the Creative Commons Attribution 4.0 International License (CC BY 4.0), which permits

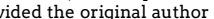
and source are credited. 
completed the survey, a semi-structured focus group interview was conducted to receive feedback on the game play and the impact of participating (Appendix A - see attached). Study authors served as focus group facilitators, taking notes for theme analysis. All data was anonymized before analysis. This study was IRB approved.

The game, "Well, for Me..." consists of questions which players take turns answering that require varying degrees of self-disclosure. For example one participant might draw the question, "What event in your life has led you to grow the most?" or "What is the greatest thing you have ever witnessed?" The subject would read the question aloud and answer it to the best of their ability. The other participants then reinforce the discloser for answering in the form of applause tokens. Then play would continue to the next participant. Play ends when the allotted time ends or when a previously determined number of rounds has been completed.

Many questions are designed to highlight shared experiences and relatability. Other questions are designed to spotlight unique characteristics or background that would be of interest. Residents are informed that their disclosures will be protected and will not result in negative consequences including stigmatization or retaliation. Taken together, the game is designed to get participants talking to each other in a way that initiates the process of connection and acceptance.

The question bank used in the game was created by the investigator after multiple rounds of refinement by a diverse group of volunteers, including those with non-Judeo Christian traditions, non-primary English speakers and diverse ethnicities. The scoring mechanism consists of each player voluntarily giving any amount of colored "applause tokens" to the other players for what they deem to be a good answer. The game was administered to multiple groups and lasts an average of 35-45 minutes.

Upon completion of the game, participants completed a mixed-methods survey consisting of ten questions and demographics (Table 1). The initial survey design was created by the investigator, and subsequent refinements for clarity and brevity were completed by the graduate medical education and emergency medicine staff. The survey answers consisted of five options: strongly disagree (1), disagree (2), neutral (3), agree (4), and strongly agree (5).

\section{RESULTS}

Forty-seven of a possible $70(67 \%)$ participants completed the written survey. The results are presented below with question nine reverse scored to account for the inverse wording on the survey. Twenty of the participants were female and twenty-six male with one unknown. Internal consistency of the survey was good (Cronbach's alpha $=0.83$ ). The results of the survey (Table 1; Figure 1) supported the assertion that participants felt the game facilitated positive disclosure and connection. For example, $93 \%$ of participants felt that the game helped them feel more connected to the other participants (Question 7).

Table 1: Survey Results

\begin{tabular}{|l|l|l|}
\hline Survey Item & Mean & SD \\
\hline 1. I feel better about my life after this activity & 3.12 & 1.00 \\
\hline 2. I feel like this activity helped me know myself better & 3.36 & 1.07 \\
\hline 3. I feel like my group are better friends after this activity & 4.07 & 0.90 \\
\hline 4. I hope to do this activity again soon & 3.56 & 1.19 \\
\hline 5. I know my coworkers much better because of this activity & 4.06 & 0.79 \\
\hline $\begin{array}{l}\text { 6. I better understand that I am not alone in what is going on in } \\
\text { my life }\end{array}$ & 3.79 & 1.02 \\
\hline $\begin{array}{l}\text { 7. This activity helped me feel more connected with my fellow } \\
\text { residents }\end{array}$ & 4.30 & 0.66 \\
\hline $\begin{array}{l}\text { 8. This activity helped me see a new perspective on my life } \\
\text { 9. This activity was a waste of time (Inverted score) }\end{array}$ & 3.26 & 1.07 \\
\hline 10. This activity was enjoyable & 4.02 & 1.07 \\
\hline
\end{tabular}

Noted themes support the survey data in that those items that scored higher deal with: knowledge of and connection to others in the group and playing the game as an enjoyable activity. Understanding and bonding with each other is necessary to combat against stressful situations they face in daily work. The idea of bonding came up multiple times in the open comments. This closeness allows the residents to feel comfortable enough to "offer advice to someone who needs help" (participant comment focusing on healthy responsibility and standards).

\section{Proportion of Responses}

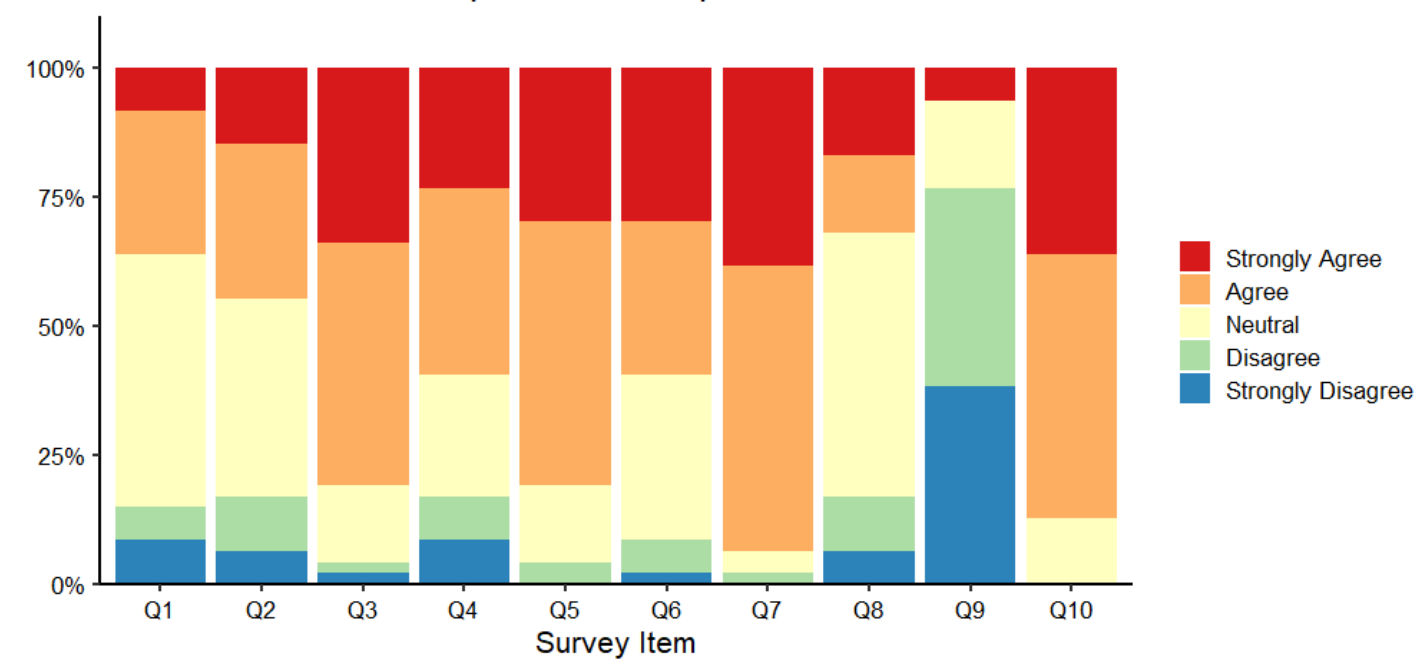

Figure 1: Proportion of Responses 


\begin{tabular}{|c|c|}
\hline Theme & Example responses \\
\hline \multicolumn{2}{|c|}{ What did it feel like to answer these questions? } \\
\hline Pleasant emotions & "Felt good" "A mental break" "Refreshed" "Fun" \\
\hline Thought provoking & "Made me think about things I usually wouldn't" \\
\hline Stressful & "Scared to share" "Exposing" "Sometimes awkward because they are really personal" \\
\hline Self-preservation & "Not know or trust people at work at first" \\
\hline Bonding & "Connected" "Open" "Use as an opportunity to let others know about me" \\
\hline \multicolumn{2}{|c|}{ What did you learn from playing this game? } \\
\hline Peers & $\begin{array}{l}\text { "Learned about others more than myself" "Aspects of other's lives" "Personalities of } \\
\text { peers" }\end{array}$ \\
\hline Similarities & $\begin{array}{l}\text { "How similar I would have answered" "Similarities" "Relatable" "We're different with the } \\
\text { same core" }\end{array}$ \\
\hline \multicolumn{2}{|c|}{ What was the best part of playing? } \\
\hline Learning about others & "Learning about everybody" "Getting to know other people" \\
\hline \multicolumn{2}{|c|}{ What was the worst part of playing } \\
\hline Fear of other's reactions & $\begin{array}{l}\text { "Sharing personal information and getting judged and judging others" "Answering the } \\
\text { questions to an audience" "Having to reveal personal details- filtering" }\end{array}$ \\
\hline \multicolumn{2}{|c|}{ Were there any questions you think were not good to ask? } \\
\hline Regrets questions & $\begin{array}{l}\text { "What did you learn from a recent embarrassing moment?" "At what time did it feel like } \\
\text { life was unfair to you?" "What opportunity do you feel like you missed out on?" }\end{array}$ \\
\hline \multicolumn{2}{|c|}{ What was the outcome of playing this game? } \\
\hline Pleasant emotions & $\begin{array}{l}\text { "Happiness" "No worries" "Silly" "My brain doesn't feel fried from answering all these hard } \\
\text { questions" "More relaxing" }\end{array}$ \\
\hline Shared peer knowledge & "Getting to know your co-workers" "All revealing ourselves helps create something" \\
\hline Bonding & "Fosters positive connection" "Bonding" \\
\hline \multicolumn{2}{|c|}{ What could be done to make this activity more meaningful? } \\
\hline Questions & $\begin{array}{l}\text { "Everyone answer the same question" "All answer more meaningful questions" "Rate } \\
\text { questions according to difficulty" }\end{array}$ \\
\hline Environment & "Quieter background" "Wine" "Play after hours in a more relaxed environment" \\
\hline
\end{tabular}

\section{DISCUSSION}

The American Medical Association categorizes resident well-being into six categories; nutrition, fitness, emotional health, preventative care, and mindset and behavioral adaptability [11]. These categories provide a framework to develop interventions that target specific components of well-being. For both empirical and practical reasons, targeted interventions are preferred because they allow us to understand how an intervention worked and provide flexibility for program leaders to address struggling areas.

The category of interventions that target emotional health seek to provide opportunities to relax and "re-energize," by developing coping mechanisms to handle the high-stress nature of residency. The category of emotional health aligns closely with the Core Emotional Needs (CEN) arising from Positive Schema Therapy $[12,13]$. CEN is a useful framework to help identify areas for targeted intervention that could result in improved resident wellness. The Core Emotional Needs consist of: Connection and acceptance, Healthy autonomy and performance, Reasonable limits, and Healthy responsibility and standards.

Although initially studied with young children, the CEN are an efficacious way to think about young professionals. For example, the need of healthy autonomy and performance is related directly to the idea of graduated autonomy espoused by Accreditation Council for Graduate Medical Education. As residents develop skills and judgement, they need to be given more autonomy and responsibility. If this graduated autonomy is not granted quickly enough, the resident will experience frustration. Conversely, disproportional independence leads to anxiety [14]. The idea of graduated autonomy also ties in to the CEN of healthy responsibility and standards, which supposes higher minimum expectations at higher level of maturity. The CEN of reasonable limits is manifest not only in limits set by those in authority but also our peer group and social norms.

Although all of the Core Emotional Needs should be addressed to improve wellness, graduate medical education (GME) wellness interventions perhaps, focus most on the last: connection and acceptance.

Working long hours in residency can lead to loneliness, and this social isolation, combined with loss of friends and support systems brought on by moving to a new environment, may have a significant impact on wellness with increased burnout [7]. People are often hesitant to develop intimate connections and disclose personal details that could initiate the bonding process with someone with whom no prior relationship exists. Residency is a difficult period to develop nurturing friendships secondary to time restraints and rotating schedules. Yet this interpersonal connection and engagement is necessary to thrive.

While playing this game was rated as a pleasant activity, it accomplished more than creating a diversion. By learning about the backgrounds, fears and drives of fellow residents, residents, "Can avoid unnecessary strife." (Participant comment focused on reasonable limits). Another participant commented that, "All revealing ourselves helps create something." That "something" could be connection and acceptance, which will help the residents on those days when they really need it.

Several participants noted "Anxiety about revealing myself" as a barrier to disclosure. Experiences of "healthy stress" (e.g., temporary stress that improves performance) could be valuable and research supports the notion of addressing or confronting negative emotions $[15,16]$. The gamification of the content helps mitigate this fear by providing increased motivation for disclosing through the use of the applause tokens. In fact, the more participants revealed, the more they were rewarded by other participants.

The game was intended to cause some degree of introspection; however, those survey items scored lowest. This is consistent in the comments section as well. Very few noted learning something about themselves whereas many noted learning about others. It is possible that group activities are not the most effective forum for engendering introspection. However, the literature regarding the benefits of introspection are mixed at best and, under certain circumstances, introspection can even lead to negative outcomes [17]. If encouraging introspection is the goal of the researcher or administer, future iterations could adapt "Well, For Me..." for solo play, coupled with a journaling experience, to encourage introspection.

Although unstructured social gatherings like going out for drinks are popular in residencies, there is no evidence that they benefit resident wellness and may lead to harmful substance-related coping mechanisms [18]. Playing "Well, For Me..." demonstrated the capacity to provide the connection and acceptance from peers necessary to limit social isolation and assist with resident wellness. With limited wellness strategies to draw from, as many proven activities as possible are needed to help combat burnout.

Important limitations of present study include the small sample size and use of an un-validated survey tool. The possibility of singular interviews, instead of focus groups, may also further delineate more sensitive responses and help avoid peer pressure leading to bias and skewed results. We do not know if participating in "Well, For Me..." had long-term benefits. The use of baseline and long-term data would strengthen 
the study and show behavior changes associated with further reflection. Future applications of "Well, For Me..." will include follow-up measures.

Lastly, although not powered to fully address the issue, there were no significant differences found between male and female responses. Future research is needed on frequency, group mix, and setting of playing "Well, For Me."

\section{CONCLUSION}

By seeing each other as individuals, not the competition or the weak link, we humanize each other and make allowance for the little quirks we all possess. This is a natural process that usually takes considerable time to progress. In residency, when wellness is at its lowest, we sought to speed up this process. "Well, For Me..." may provide residency leaders with an effective, low-stakes tool to begin the bonding process. Importantly, "Well, For Me..." can provide an opportunity for self-disclosure in a safe environment, free from retaliation and stigmatization. This intervention with the intention of accelerating connection and acceptance should be tried in other residency settings and disciplines.

Acknowledgments: The authors would like to acknowledge Bing Parkinson for helping collect data.

\section{REFERENCES}

1. Around J, Tango J, Walker I, et al. An Evidence-based, Longitudinal Curriculum for Resident Physician Wellness: The 2017 Resident Wellness Consensus Summit. West J Emer Med. 2018; 19(2).

2. Ripp JA, Privitera MR, West CP, Leiter R, Logio L, Shapiro J, et al. Well-Being in Graduate Medical Education: A Call for Action. Acad Med. 2017 Jul;92(7):914-7.

3. Diller D, Osterman J, Tabatabai R. Qualitative Analysis of Well-being Preparedness at an Emergency Medicine Residency Program. West J Emer Med. 2019;20(1).

4. Hart D, Paetow G, Zarzar R. Does Implementation of a Corporate Wellness Initiative Improve Burnout? West J Emer Med. 2018;20(1).

5. Runyan C, Savageau J, Potts S. Weinreb. Impact of a family medicine resident wellness curriculum: a feasibility study. Med Edu Online; 2016. p. 21.

6. Lin M, Battaglioli N, Melamed M, Mott SE, Chung AS, Robinson DW. High Prevalence of Burnout Among US Emergency Medicine Residents: Results From the 2017 National Emergency Medicine Wellness Survey. Ann Emerg Med. 2019 Nov;74(5):682-90.
7. Perina DG, Marco CA, Smith-Coggins R, Kowalenko T, Johnston MM, Harvey A. Well-Being among Emergency Medicine Resident Physicians: Results from the ABEM Longitudinal Study of Emergency Medicine Residents. J Emerg Med. 2018 Jul;55(1):101-109.e2.

8. Naci H, Ioannidis JP. Evaluation of Wellness Determinants and Interventions by Citizen Scientists. JAMA. 2015 Jul;314(2):121-2.

9. Accreditation Council for Graduate Medical Education. Summary of changes to ACGME common program requirements section VI. https://www.acgme.org/What-We-Do/Accreditation/Common-Program-Requirements/ Summary-of-Proposed-Changes-to-ACGME-Common-Program-Requirements-Section-VI. Accessed March 2019.

10. White E, Lewis J, McCoy L. Gaming science innovations to integrate health systems science into medical education and practice. Ad in Med Ed \&Practice May 2018(9). https://doi.org/10.2147/AMEP.S137760.

11. American Medical Association. Physician wellness: Preventing resident and fellow burnout - STEPS forward. https://www.stepsforward.org/modules/ physician-wellness

12. Louis J, Wood A, Lockwood G. Development and Validation of the Positive Parenting Schema Inventory (PPSI) to Complement the Young Parenting Inventory (YPI) for Schema Therapy (ST). Psych Assess 2018;30(9).

13. Louis J, Wood A, Lockwood G, Ho M, Ferguson E. Positive Clinical Psychology and Schema Therapy (ST): The Development of the Young Positive Schema Questionnaire (YPSQ) to Complement the Young Schema Questionnaire 3 Short Form (YSQ-S3). Psych Assess. September 2018.

14. Stritter FT, Baker RM, Shahady EJ. Clinical Instruction. In: McGaghie CD, Frey JJ, editors. Handbook for the Academic Physician. New York: Springer-Verlag; 1988. pp. 98-124.

15. Lempert KM, McGuire JT, Hazeltine DB, Phelps EA, Kable JW. The effects of acute stress on the calibration of persistence. Neurobiol Stress. 2018 Nov;8:1-9.

16. Markowitz JC, Milrod BL. The importance of responding to negative affect in psychotherapies. Am J Psychiatry. 2011 Feb;168(2):124-8.

17. Hixon JG, Swann WB Jr. When does introspection bear fruit? Self-reflection, self-insight, and interpersonal choices. J Pers Soc Psychol. 1993 Jan;64(1):35-43.

18. Williams D, Tricomi G, Gupta J, Janise A. Efficacy of burnout interventions in the medical education pipeline. Acad Psychiatry. 2015 Feb;39(1):47-54. 
1) What did it feel like to answer these questions? Sometimes awkward because they are really personal I felt silly

Some questions were variations of the same question Made me think about things I usually wouldn't

Fun

Frustrating, I want the other's questions, why is my question so boring?

Anxiety about how personal is the question

Uncomfortable

Felt good

About self

I had to think

Some easier, some harder, reflective

Exposing

Vulnerable but not bad in this setting to get to know each other

I needed to filter through to find what is appropriate, in another setting I would answer differently

Use as an opportunity to let others know about me

Good

Connected

Refreshed

Open

Apprehension

Not know or trust people at work at first

Good

Fun

Had to think

Don't typically open up at work

A good mental break

Fun

Scared to share

Refreshing but some questions were invasive

2) What did you learn from playing this game?

I and others need to examine the creative part of our brain

It was interesting how people reacted to questions

Resource allocation (scoring cubes)

Learn about each other

Aspects of other's lives

Learned about others more than myself

Good icebreaker

Semi forced to reveal myself

How we interact with each other

Similarities

I'm very introspective

It's ok to say anything about yourself

More social

Relatable

We're different with the same core

To be honest

Learned about the residents, not Alice (an attending)

How similar I would have answered

Personalities of peers

Can open up to coworkers
3) What was the best part of playing?

Organizing the cubes, making patterns

It was fun

All get to come together and play at lunch

Learn about each other

Getting to know each other

Learn about everyone

Learned about how people answered the questions

It did its purpose

Getting to know other people

Share things with you I wouldn't normally share

Not just me that had these blockers

A team to go over obstacles

Connection

Bonding

Got know to each other

Hearing people's perspectives

Want to play with other people

Learning about everybody

Not bring up these topics in day to day conversation

Judging others answers and giving tokens

4) What was the worst part of playing?

Not knowing the goal

Some questions were great and others not

No blind date game

Answer with people you already know a little

Felt too personal

Trying to figure out how many points to give each other

Answering the questions to an audience

None

Some questions are not as specific as they could be

Having to reveal personal details- filtering

Ended too soon

Starting

Losing

Pressure

Personal information and getting judged and judging others

Scared to share 
5) Were there any questions you think were not good to ask?

Describe, not name, your favorite color.

How would you like to be remembered?

False dichotomies (Are you closer to your mom or dad? What

makes you feel close to them? Would you rather have

constant conflict and sincere love or minimal conflict and

superficial love? Are you an introvert or an extrovert? Why

do you say that? Do you have a guilty soul or a prideful soul?)

Picture yourself in a forest. Describe it.

What's the greatest...? (What is the greatest lesson you have

learned? What the greatest thing you have personally

witnessed?)

No

Is it easier to do or to be? Explain.

Yes/no answers (Do you ever feel like someone is mad at

you? When?) (Do you have an impossible dream?)

What did you dread about today should be changed to "not

look forward to" (What did you dread about today? Did it

turn out like you thought it would?)

What have you grown in the most?

No

What do you most fear?

How do you like your eggs cooked? Why?

In high school, what 'clique' would you have been in? Band geek, jock, punk

Regrets questions (what did you learn from a recent

embarrassing moment? What area of your life do you have

the lowest expectations? At what time did it feel like life was unfair to you? What seemed like a major failure in your life that turned out to be a blessing? What opportunity do you feel like you missed out on?

Skipped negative questions,

Weren't comfortable with personal questions

6) What was the outcome of playing this game?

Research agenda

More confused

Getting to know your co-workers

Relaxing

My brain doesn't feel fried from answering all these hard questions

Some could be informal questions

"He won"

30 minutes passed

Enjoyable

"He won"

Got to know each other better

Fun

Nice with recent long hours
Relaxing

More relaxing

Reduce social tension

Break down walls

Not such a judgmental environment

Common ground

Fosters positive connection

All reveal ourselves help create something

Connection

Bonding

Happiness

Laughing

Get feedback/ big picture

Judge yourself very strictly

Offer advice to someone who needs help

Happy

Silly

No worries

I know them better

Can open up to coworkers

Laughing, and opening up to talk to coworkers

7) What could be done to make this activity more meaningful? Everyone answer the same question

Pictures

Do it closer to the end (or middle) of the year

Have everyone answer the question

Take out "failure" questions

Design the game so you answer more questions

Betting on answers

Play every month

Rate questions according to difficulty

All answer more meaningful questions

More precise about applause tokens

More cubes

Play every week

Quieter background

More people

How would I compare before and after

After a few rotations

Not during working hours

Play after hours in a more relaxed environment 